\title{
Der Arbeitskreis Neurosonografie stellt sich
}

\section{vor}

Sehr geehrte Frau Kollegin, sehr geehrter Herr Kollege,

Der Arbeitskreis Neurosonografie der ÖGUM wurde im Oktober 2014 im Rahmen des 3-Ländertreffens Ultraschall aus der Taufe gehoben und möchte sich Ihnen vorstellen.

Arbeitskreisleiter ist Priv. Doz. Dr. Gerd Bodner von der Universitätsklinik für Radiologie und Nuklearmedizin der Medizinischen Universität Wien. Er gilt sowohl einer der Pioniere dieser Disziplin als auch mit nunmehr 20 Jahren Erfahrung als einer der weltweit führenden Experten in diesem Bereich. Die Fort- und Weiterbildung in der Methode, die ihn seit Anbeginn seiner ärztlichen Tätigkeit begleitet, ist ihm stets ein großes Anliegen. Stellvertretende Arbeitskreisleiterin ist Ass. Prof. Priv. Doz. Dr. Doris Lieba-Samal von der Universitätsklinik für Neurologie der Medizinischen Universität Wien. Ihr beruflicher Schwerpunkt liegt in der Elektroneurodiagnostik, für die sie den Ultraschall als eine wertvolle komplementäre Methode kennen lernte und nun 4 Jahre Erfahrung damit mitbringt.

An bisherigen gemeinsamen Projekten sind mehrere Publikationen, Kurse und die Organisation eines Internationalen Kongresses zum Thema Ultraschall zu nennen.
Die Entscheidung zur Etablierung dieses Arbeitskreises fiel aufgrund der zunehmenden Bedeutung des Ultraschalls in der Diagnostik von Erkrankungen peripherer Nerven sowie der immer häufigeren Anwendung im klinischen Alltag. Seine Geschichte begann vor 25 Jahren mit ersten Publikationen zu Tumoren peripherer Nerven und dem Karpaltunnelsyndrom. Zwischenzeitlich ist der Ultraschall etabliert in der Diagnostik von Nervenkompressionssyndromen (z.B. Karpaltunnelsyndrom), Tumoren und Traumata. Ein Beispiel für einen unauffälligen Befund sehen Sie in oAbb.1.

Diese Entwicklung ging Hand in Hand mit dem technischen Fortschritt, welcher die kommerzielle Verfügbarkeit von hochauflösenden Sonden möglich machte. So sind mittlerweile auch Nerven mit einem Durchmesser von unter $1 \mathrm{~mm}$ bzw. einzelne Nervenfaszikel zuverlässig beurteilbar. Als momentaner Grenzbereich sind die Polyneuropathien zu nennen. Die Bedeutung des Ultraschalls hinsichtlich Diagnose, therapeutischem Erfolg und Prognose sind Gegenstand intensiver Forschung. Als einer der Schwachpunkte der Methode wird stets die Untersucherabhängigkeit genannt. Somit ist eine der primären Aufgaben dieses Arbeitskreises, die Ausbildung $\mathrm{zu}$ vereinheitlichen und Standards für Dokumentation und Befundung auszuarbeiten.

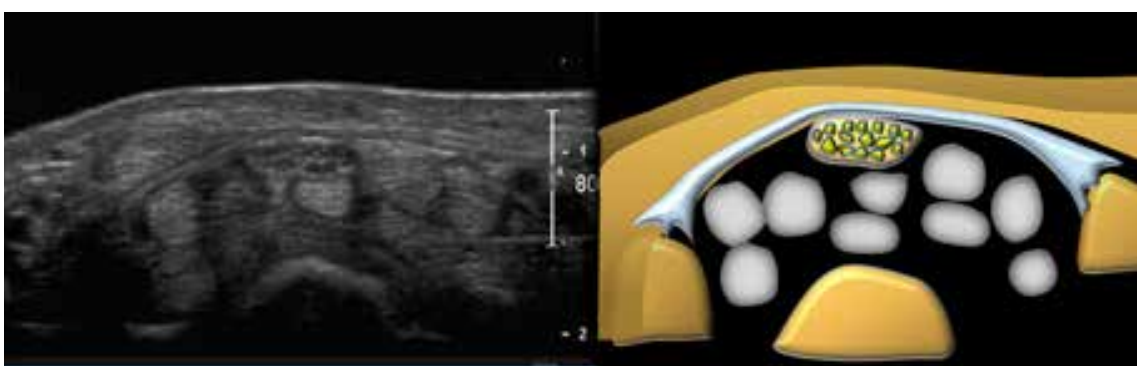

Abb. 1. N. medianus im Karpaltunnel (Grafik: G. Bodner, Wien).

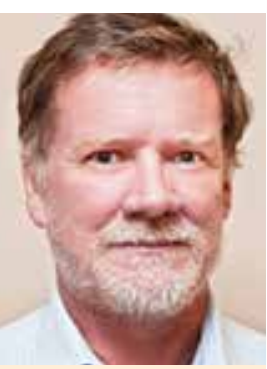

Gerd Bodner

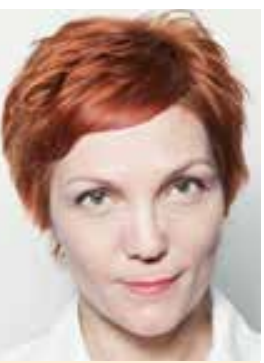

Doris Lieba-Samal
Wenn Sie Interesse an unserem Arbeitskreis haben, würden wir uns sehr freuen, von Ihnen zu hören. Wir sind offen für Anregungen, Ideen und Verbesserungsvorschläge. Bitte per email an: gerd.bodner@ meduniwien.ac.at oder doris.lieba-samal@meduniwien.ac.at

\section{Mit kollegialen Grüßen}

Gerd Bodner, Doris Lieba-Samal 